\title{
The sensitivity of tropical convective precipitation to the direct radiative forcings of black carbon aerosols emitted from major regions
}

\section{Wang}

Center for Global Change Study and the Joint Program on the Science and Policy of Global Change, Massachusetts Institute of Technology, Cambridge, MA 02139, USA

Received: 23 March 2009 - Revised: 8 September 2009 - Accepted: 15 September 2009 - Published: 2 October 2009

\begin{abstract}
Previous works have suggested that the direct radiative forcing (DRF) of black carbon (BC) aerosols are able to force a significant change in tropical convective precipitation ranging from the Pacific and Indian Ocean to the Atlantic Ocean. In this in-depth analysis, the sensitivity of this modeled effect of $\mathrm{BC}$ on tropical convective precipitation to the emissions of $\mathrm{BC}$ from 5 major regions of the world has been examined. In a zonal mean base, the effect of BC on tropical convective precipitation is a result of a displacement of ITCZ toward the forcing (warming) hemisphere. However, a substantial difference exists in this effect associated with BC over different continents. The BC effect on convective precipitation over the tropical Pacific Ocean is found to be most sensitive to the emissions from Central and North America due to a persistent presence of $\mathrm{BC}$ aerosols from these two regions in the lowermost troposphere over the Eastern Pacific. The BC effect over the tropical Indian and Atlantic Ocean is most sensitive to the emissions from South as well as East Asia and Africa, respectively. Interestingly, the summation of these individual effects associated with emissions from various regions mostly exceeds their actual combined effect as shown in the model run driven by the global BC emissions, so that they must offset each other in certain locations and a nonlinearity of this type of effect is thus defined. It is known that anthropogenic aerosols contain many scatteringdominant constituents that might exert an effect opposite to that of absorbing BC. The combined aerosol forcing is thus likely differing from the BC-only one. Nevertheless, this study along with others of its kind that isolates the DRF of $\mathrm{BC}$ from other forcings provides an insight of the potentially important climate response to anthropogenic forcings particularly related to the unique particulate solar absorption.
\end{abstract}

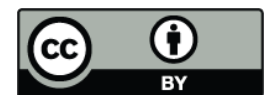

Correspondence to: C. Wang (wangc@mit.edu)
Keywords. Atmospheric composition and structure (Aerosols and particles) - Meteorology and atmospheric dynamics (General circulation; Precipitation)

\section{Introduction}

The absorption of solar radiation in the atmosphere by black carbon (BC) aerosols leads to a heating of the atmosphere and a strong cooling at the Earth's surface particularly over the land (e.g., Hansen et al., 1998; Haywood and Ramaswamy, 1998; Satheesh and Ramanathan, 2000; Ramanathan et al., 2001; Wang, 2004). A previous study has indicated that, owing to the unique features of the direct radiative forcing (DRF) of $\mathrm{BC}$ to the Earth-atmosphere system, the climatic effect of this type of aerosols is more significant at the regional scale than global scale, and on hydrological cycle than surface air temperature (Wang, 2004). The most substantial modeled effect in the regional scale of $\mathrm{BC}$ occurs in tropical convective precipitation particularly over Pacific Ocean, exemplified by an enhancement of up to $15 \%$ in the northern precipitation band of the interhemispheric convergence zone (ITCZ) and a nearly $30 \%$ reduction in the southern band (both on a zonal mean basis), or a clear northward shift of ITCZ. These findings have been supported by other independent studies using different climate models (e.g., Roberts and Jones, 2004; Chung and Seinfeld, 2005).

The most significant effects of $\mathrm{BC}$ on tropical precipitation occur in places (e.g., ITCZ) that are remote from major source regions of BC (i.e., Northern Hemisphere and over land). Therefore, such an effect must have been implemented first through an alteration to the atmospheric general circulation and then propagated into remote oceanic regions (e.g., Menon et al., 2002; Chung and Ramanathan, 2003; Wang,

Published by Copernicus Publications on behalf of the European Geosciences Union. 
2004, 2007; Roberts and Jones, 2004). It has been further suggested that both the pattern and forcing mechanism of the modeled precipitation change in Pacific ITCZ caused by BC are similar to those generated by El Niño/Southern Oscillation (ENSO) (Wang, 2007). This implies that the modeled convection and precipitation change over the entire tropical Pacific could be triggered by $\mathrm{BC}$ forcings only over the eastand west-most Pacific.

It is important to indicate that the actual changes in the tropical convection and precipitation could be attributed to many factors besides the DRF of BC. In addition, the anthropogenic aerosols contain many other constituents such as scattering-dominant sulfate that might exert an effect opposite to that of absorbing BC (e.g., Rotstayn and Lohmann, 2002). Nevertheless, the type of studies that isolated the DRF of BC from other forcings can still provide a critical insight of a potentially important climate response to anthropogenic forcings. In fact, when the large-scale dynamics is concerned, the response of tropical convection and precipitation obtained from BC-only studies is consistent with the results of recent idealized modeling studies based on asymmetric extratropical thermal forcings (e.g., Broccoli et al., 2006; Kang et al., 2008), and certainly with the result of Rotstayn and Lohmann (2002) obtained by applying the indirect forcing of sulfate that has a dominant cooling effect over the Northern Hemisphere. Note also that despite the clear drawback of the current global climate models in representing individual and local convective events due to their coarse resolutions, these models are able to produce many important large-scale convection and precipitation features (Emanuel et al., 1994; Randall et al., 2007) and thus is useful in the task to study the DRF of aerosols on large-scale convection and precipitation.

This study aims to further examine the previous findings/hypotheses on the effect of $\mathrm{BC}$ on tropical precipitation and to study the sensitivity of such effect to the DRF of $\mathrm{BC}$ over different geographical locations. For this purpose, an interactive aerosol-climate model used in previous studies (Wang, 2004, 2007) is also adopted but driven by emissions only from a selected region from the world. The results from these simulations are compared with the previous runs with globe $\mathrm{BC}$ emissions and thus the climate effects corresponding to each of these regional emissions are identified. The nonlinearity of $\mathrm{BC}$ direct radiative effect has also been revealed.

\section{Methods}

An interactive BC aerosol-climate model (Wang, 2004) developed based on the Community Climate Model version 3 (CCM3) of the National Center for Atmospheric Researches (Kiehl et al., 1998) is used in this study. The model has a 2.8 by 2.8 degree horizontal resolution and 18 vertical layers. Various processes of $\mathrm{BC}$ aerosols from emissions, dry

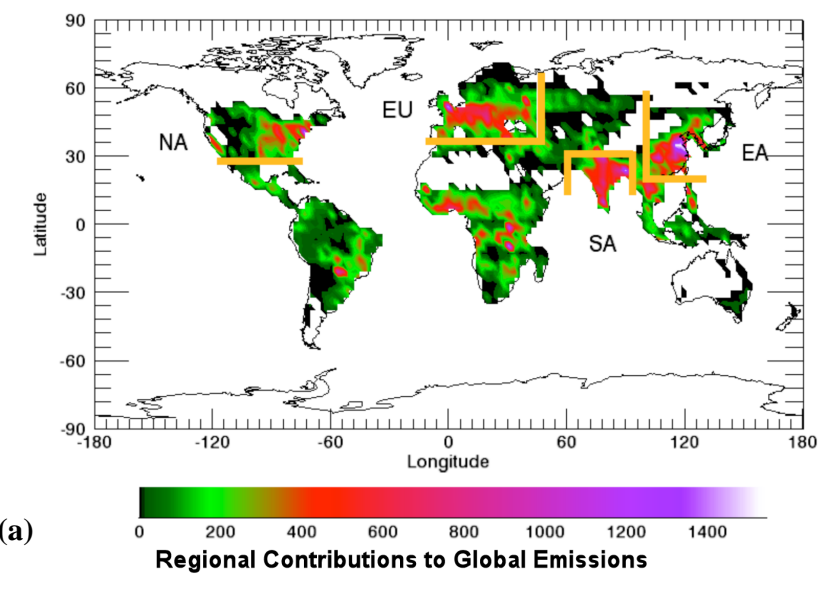

(a)

(b)

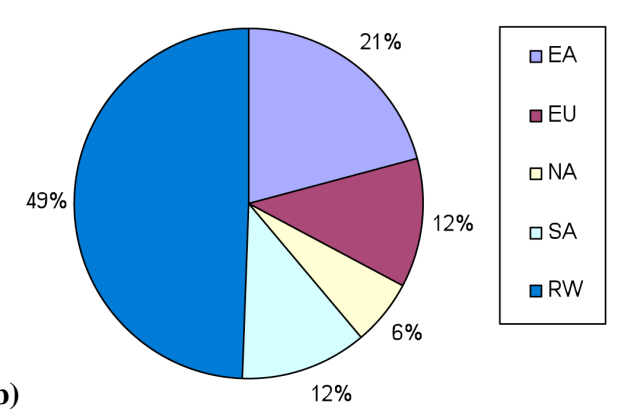

Fig. 1. (a) Emissions distribution of $\mathrm{BC}$ in $\mathrm{kgC} / \mathrm{km}^{2} / \mathrm{year}$. All emissions are applied constantly through seasons. Orange lines mark the boundaries separating major $\mathrm{BC}$ emission regions. (b) The percentage contributions of regional $\mathrm{BC}$ emissions to the global total.

deposition, gravitational sedimentation, and wet removal (by both liquid and ice precipitating particles) are included in the model and calculated at each climate model time step (20 min) by using (when applies) CCM3 produced winds, temperature, water vapor concentration, and precipitation rates. When the option is chosen, the radiative effect of $\mathrm{BC}$ aerosols is directly calculated in the radiation module of $\mathrm{CCM} 3$ using predicted $\mathrm{BC}$ distributions rather than prescribed albedo or forcings. Note that the much more complicated and poorly understood indirect effects of BC aerosols are excluded in the current simulations. The idealized configuration does not include other aerosol constituents. This study is emphasized on the climatic response appearing in tropical convective precipitation to the direct forcing of black carbon. More details of the model are provided in Wang (2004).

The BC emissions around the globe derived in Wang (2004) have been separated into 5 regions, namely East Asia (EA), Europe (EU), North America (NA), South Asia (SA), the rest of the world outside above regions (RW). Their percentage contribution in the global total BC emissions is $21 \%$, $12 \%, 6 \%, 12 \%$, and $49 \%$, respectively (Fig. 1). Note that this arbitrary partition is biased toward anthropogenic emissions, 
TE

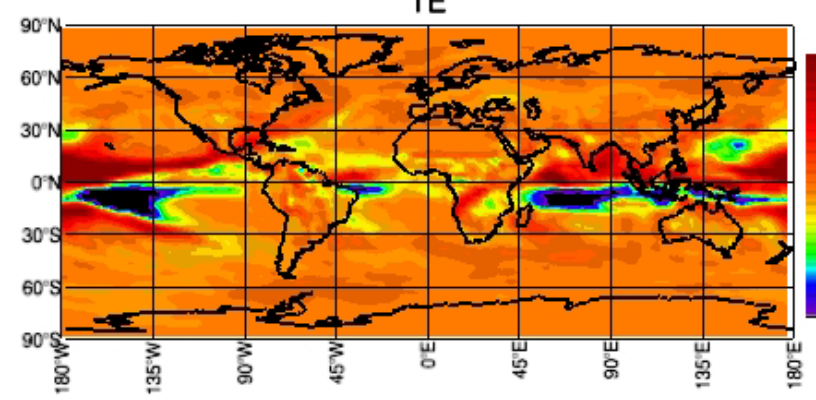

NA

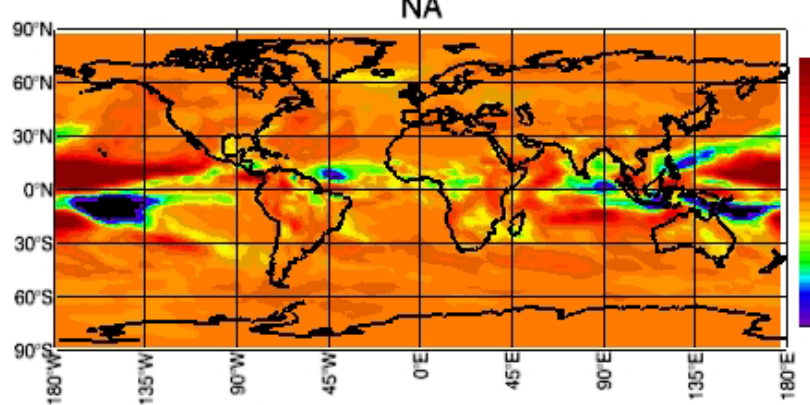

RW

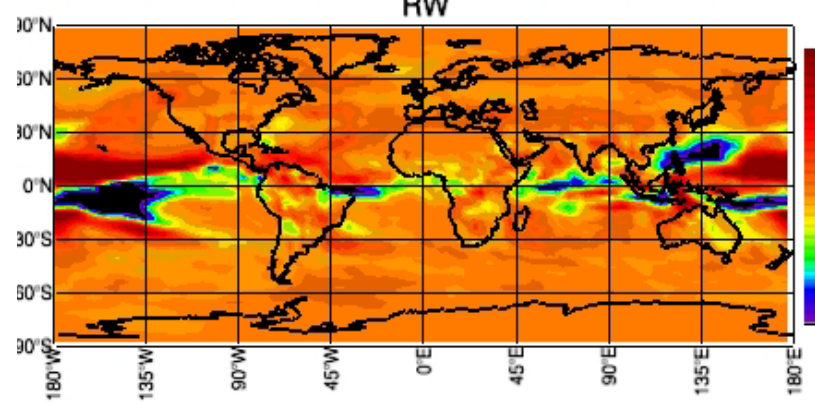

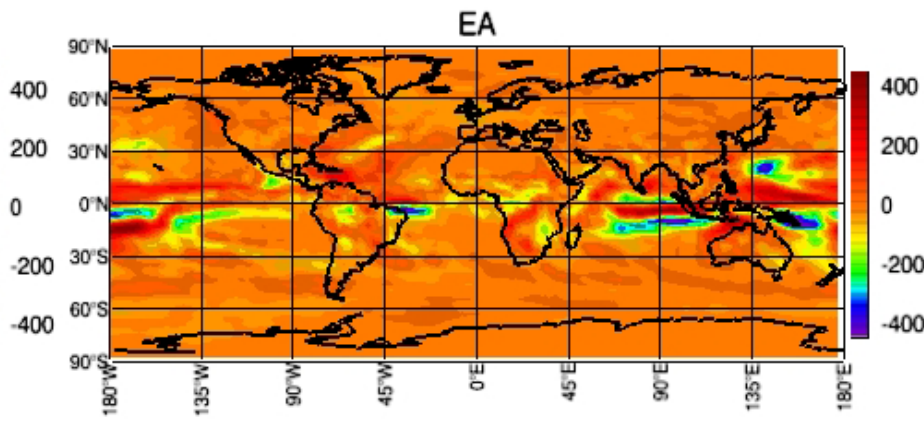

EU

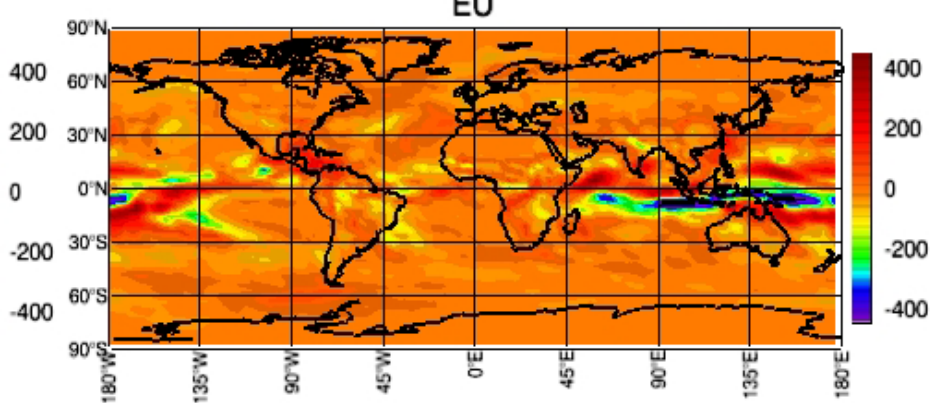

SA

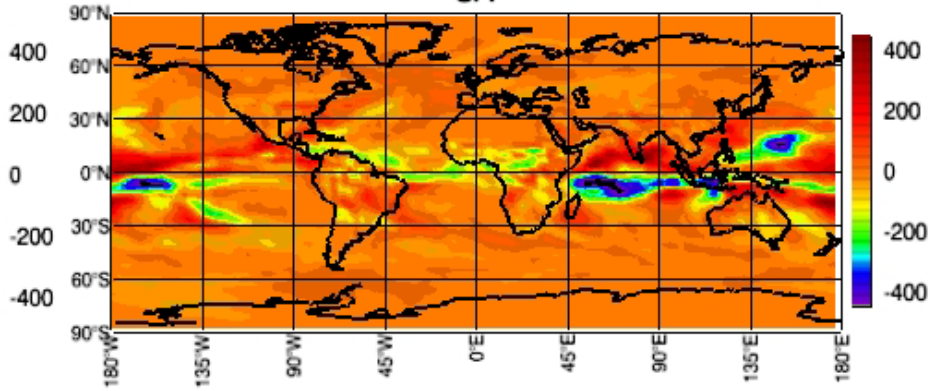

Fig. 2. Changes in annual mean convective precipitation caused by $B C$ aerosols. Results are derived from model runs driven by BC emissions from: (a) all around the globe (TE), East Asia only (EA), North America only (NA), Europe only (EU), South Asia only (SA), and rest of the world (RW). Data are year 41-60 means.

two major biomass-burning regions, i.e., Africa and South America are not separated. Five model runs are then carried out; each of these runs only includes emissions from one of these 5 regions. In addition to these five regional emission runs, results of two model runs conducted in Wang (2004), one was driven by the $\mathrm{BC}$ emissions from the globe (Total Emissions, or TE) and the one excluded direct radiative effect of BC in its radiation calculation (reference, or REF) have also been used. Except for the adopted emission data sets, all these runs excluding REF are otherwise identical.

Each of the model runs last 60 years to reach a quasiequilibrium forced by a coupled slab ocean model. The last 20 -year means of modeled outputs are used in the analysis. Comparing the difference between each of the aerosol forcing runs and the REF run isolates the effect of $\mathrm{BC}$, the same method used in Wang $(2004,2007)$. Thereafter, the words of "BC caused change" in a given quantity is referred to the difference in this quantity between the result of forcing run and that of REF run. Additionally, the results of a given variable from all the regional emission runs are summed together to form another result set, called SUM. The comparison between this set and the results of TE is used to examine the nonlinearity of various BC climate effects.

The statistical significance of all the results discussed in this paper has been evaluated using a paired t-test (Wang, 2007). To save the length of the paper, unless otherwise indicated the discussed results are statistically significant.

\section{Results}

As indicated in Wang $(2004,2007)$, the modeled changes caused by $\mathrm{BC}$ aerosols in tropical convective precipitation are most substantial over the Pacific Ocean particularly in the central and eastern part, followed by the Northern Indian Ocean. The Atlantic ITCZ is also clearly affected by BC aerosols but the strength is less significant in comparison. 


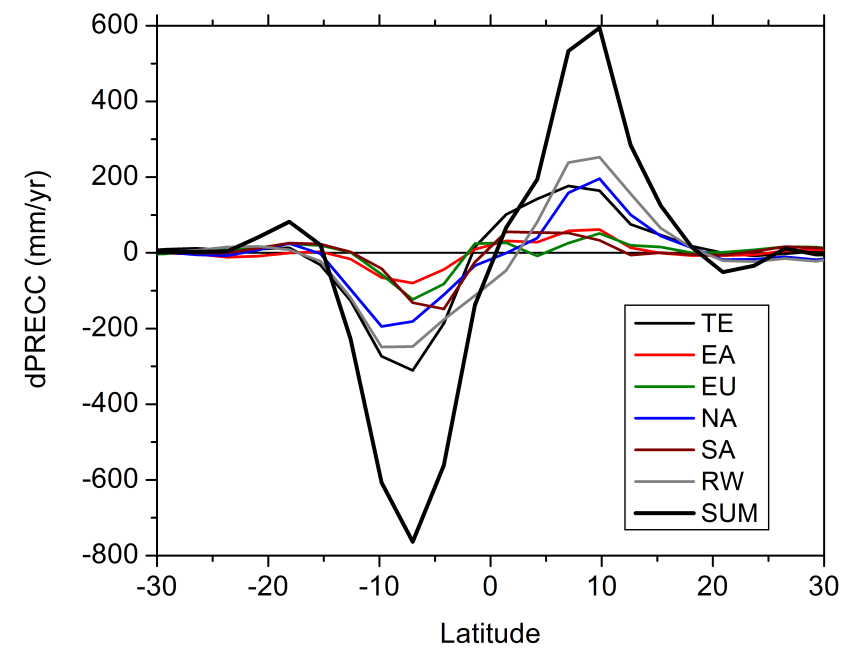

Fig. 3. Zonal means of changes in convective precipitation (mm/year) caused by BC derived from each model run. Data shown are year 41-60 means.

The above changes in convective precipitation in the Pacific and Indian Ocean ITCZ are results of three alterations in the atmospheric circulation caused by BC aerosols (Wang, 2007): a strong perturbation in the east tropical Pacific ( $180 \mathrm{~W}$ to $100 \mathrm{~W}$ in longitude) that reduces the easterly wind and is most significant in the boreal spring and summer; a pole-ward enhancement in the annual mean circulation over the Northern Indian Ocean which peaks during the boreal summer (30E-115E); and a westerly enhancement in the Western Pacific, which is strongest during the summer and fall in the Northern Hemisphere (120 E to 180 E) (see Fig. 3a in Wang, 2007).

The results of the regional emission runs indicate that emissions from all major regions can force a change in tropical atmospheric circulation and precipitation but the patterns and strengths of these changes differ (Fig. 2). Over the Pacific Ocean, the NA and RW runs show a very similar pattern of change to that in the TE run. For the pattern of change in the ITCZ precipitation over the Indian Ocean, the SA, EA and EU runs clearly resemble the results of the TE run. The most similar pattern of change to the TE run result for the Atlantic ITCZ precipitation appears in the RW run. Interestingly, a substantial difference between TE and SUM can be seen in Fig. 3, indicating the nonlinearity in BC-caused convective precipitation change. The nonlinearity is also reflected from the results that the responses in NA and RW runs are often higher than that in TE run (Figs. 2-6).

On a zonal mean base, the DRF and associated heating of $\mathrm{BC}$ are concentrated in the Northern Hemisphere away from tropics, such a forcing distribution exerts an alteration to the general circulation (Wang, 2007). A cross-equator flux of moist static energy (MSE) caused by BC effect is found from the Southern Hemisphere to Northern Hemisphere in the lower troposphere while a compensate flux in the opposite direction appears in the upper troposphere (Fig. 4), clearly indicating a displacement of ITCZ toward the warming Northern Hemisphere. These results are consistent in the hemispheric large-scale sense with the ones obtained from idealized asymmetric heating simulations (e.g., Broccoli et al., 2006; Kang et al., 2008). There is a clear seasonality associated with the cross-equator MSE fluxes, the lower tropospheric flux of MSE peaks in the boreal summer in the TE run. In the regional emission runs, RW and NA runs produced the lower tropospheric MSE fluxes that are closest to the TE result in quantity.

A unique character of the $\mathrm{BC}$ DRF is its non-uniform distribution along not only the meridional but also the zonal direction, differing clearly from the uniform zonal distribution of thermal heating in a given hemisphere in the idealized simulations (e.g., Kang et al., 2008). As a result, the crossequator meridional MSE flux in the lower troposphere caused by $\mathrm{BC}$ also has a non-uniform distribution horizontally that peaks over tropical Pacific, followed by Indian and then Atlantic (Fig. 5). This distribution must be related to BC loading over certain part of the world. It is found that over the east tropical Pacific, the meridional MSE flux derived from the NA and RW runs exceed that from the TE run. In rest of the model runs, the same flux caused by BC aerosols is clearly lower than the flux seen in the NA and RW runs (note that the EU run provides the smallest flux that lacks statistical significance and is almost negligible in comparison). BC aerosols emitted from North and South America enter the east tropical Pacific carried by the easterly trade winds and thus are mainly concentrated in the lowermost atmosphere near the Equator. This distribution is very persistent and causes an effective warming in the lower troposphere over water and thus a pressure gradient along the Equator almost throughout all seasons. The above dynamic perturbation over the Eastern Pacific also propagates to the Western Pacific as shown in the changes in meridional MSE flux over there. The fluxes derived from the NA, RW, and EA runs all show a substantial strength comparing to the TE run. The meridional MSE flux over the Indian Ocean is mainly sensitive to the emissions from south Asia (SA). RW aerosols, primarily those from Africa, are the most effective ones in changing the atmospheric circulation and associated precipitation in the Atlantic ITCZ. In addition to the RW emissions, BC aerosols from EA can also cause a clear change in the Atlantic ITCZ.

Specifically in Pacific ITCZ, Wang (2007) suggested that $\mathrm{BC}$ could cause a surface temperature or pressure anomaly that favors a gradient from west to central and east Pacific and thus an anomalous westerly over the region. The results of surface temperature and wind anomalies again suggest that the precipitation change over tropical Pacific ITCZ is most sensitive to the emissions from NA and RW (mostly from Central America sector of RW) (Fig. 6). 
Zonal $[\mathrm{V} * \mathrm{MSE}]$ of the Lower Troposphere: TE
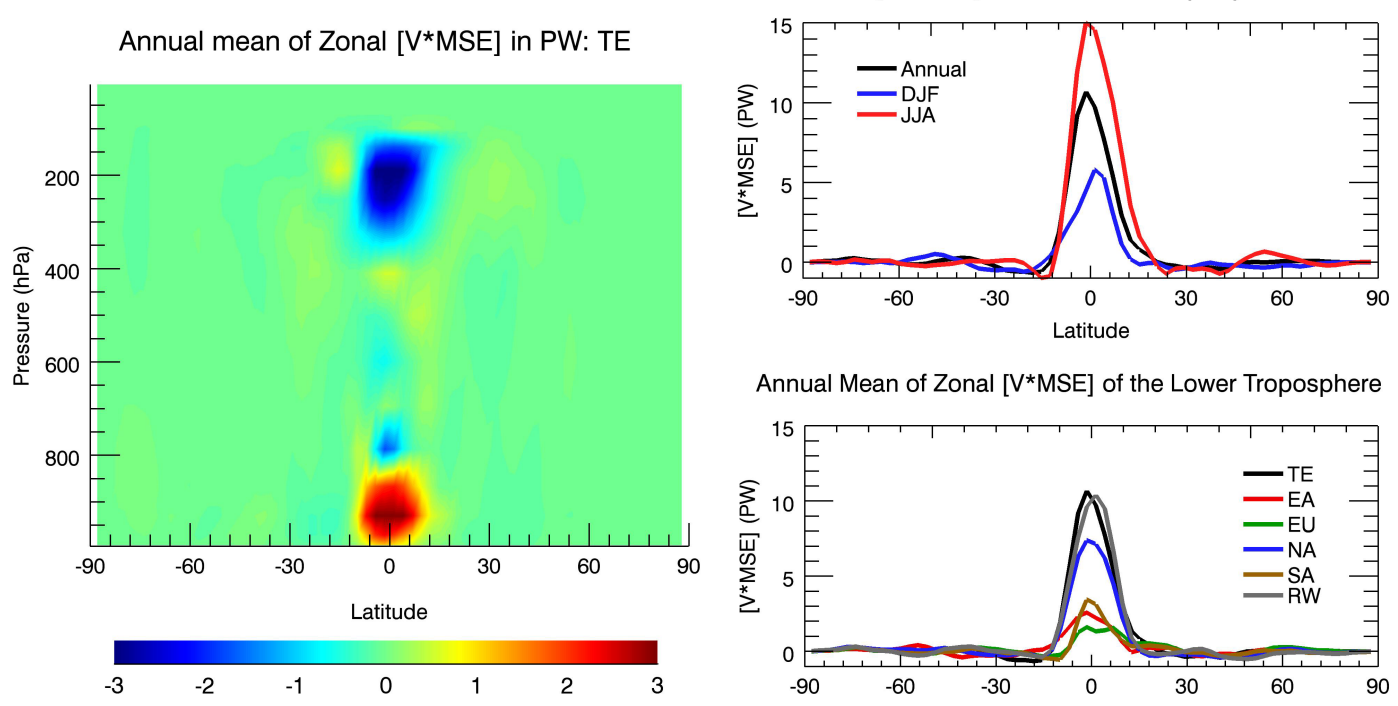

Annual Mean of Zonal [V*MSE] of the Lower Troposphere

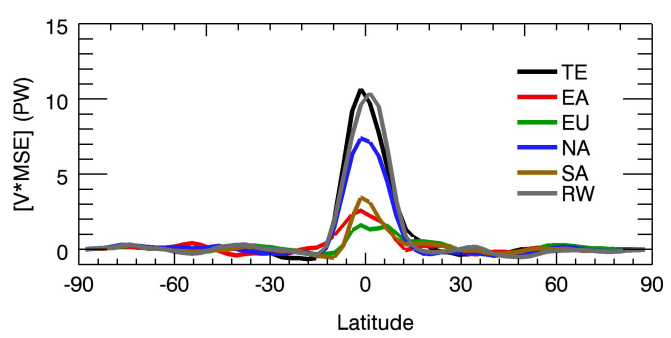

Fig. 4. Left panel: Zonal mean meridional flux of moist static energy (MSE) from the TE run. Upper panel on the right: Zonal mean meridional MSE fluxes as annual mean, December-January-February (DJF) mean, and June-July-August (JJA) mean, accumulated over the 4 lowermost model layers (from surface to $\sim 850 \mathrm{hPa}$ ), derived from TE run. Lower panel on the right: Annual mean meridional MSE fluxes accumulated over the 4 lowermost model layers derived from different runs. Here: $\mathrm{MSE}=c_{p} T+L_{v} q+\phi ; c_{p}$ is the specific heat at constant pressure, $L_{v}$ the latent heat of vaporization, $T$ the air temperature, $q$ the specific humidity (water vapor mixing ratio), and $\phi$ the geopotential. The unit is in PW. All data are last 20-year means.

Annual Mean $\left[V^{\star} M S E\right]$ in the Lower Troposphere (TW): TE

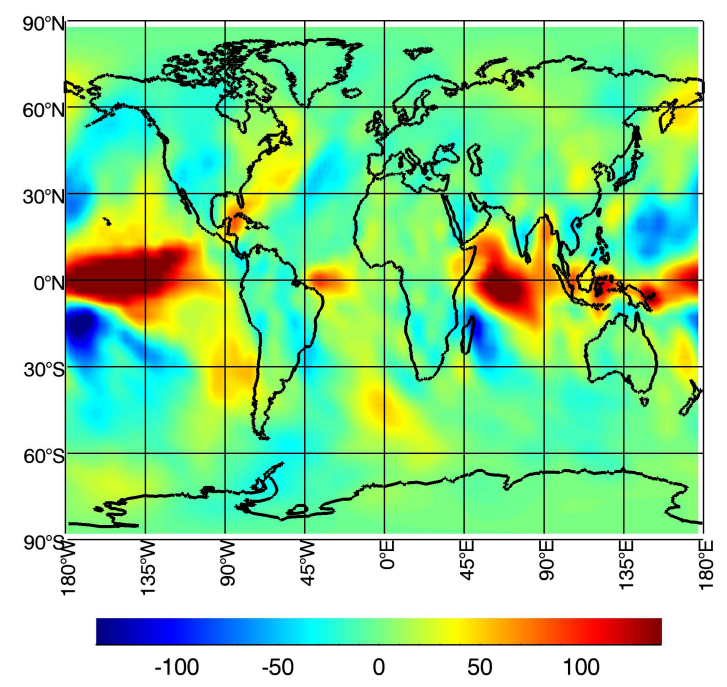

Tropical-Mean $\left[\mathrm{V}^{\star} \mathrm{MSE}\right]$ in the Lower Troposphere: TE

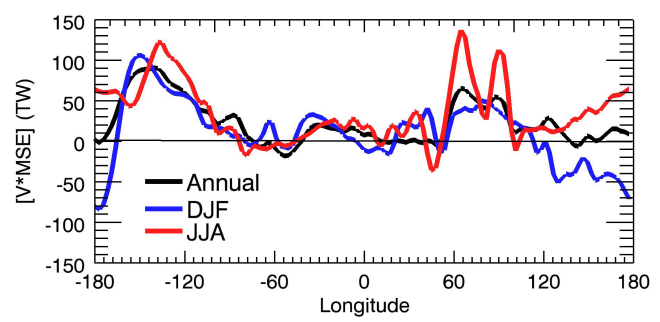

Annual Tropical-Mean [V*MSE] in the Lower Troposphere

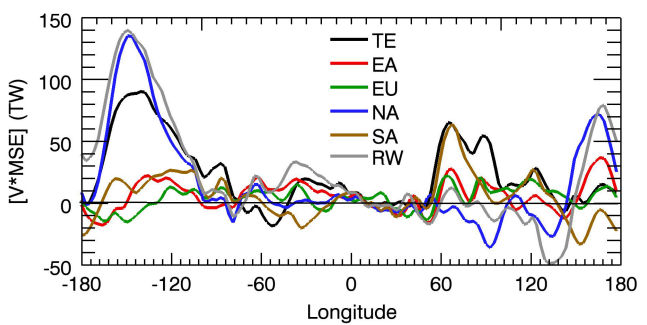

Fig. 5. Left panel: Annual mean meridional MSE flux accumulated over the 4 lowermost model layers as functions of longitude and latitude derived from the TE run. Upper panel on the right: Tropical mean (23 S to $23 \mathrm{~N}$ ) of meridional MSE flux accumulated over the 4 lowermost model layers as annual mean, DJF mean, and JJA mean from the TE run. Lower panel on the right: The annual mean meridional MSE fluxes from different runs as accumulated values over the 4 lowermost model layers. The unit of MSE flux is in TW. All data are last 20-year means.

\section{Conclusion}

The impact of the direct radiative forcing of $\mathrm{BC}$ aerosols from various regions around the globe on tropical convective precipitation has been examined using an aerosol-climate interactive model driven by regional $\mathrm{BC}$ emissions. In a zonal mean base, the effect of $\mathrm{BC}$ on tropical convective precipitation is a displacement of ITCZ toward the forcing (warming) 
Changes in Surface Air Temperature (5S-10N Mean)

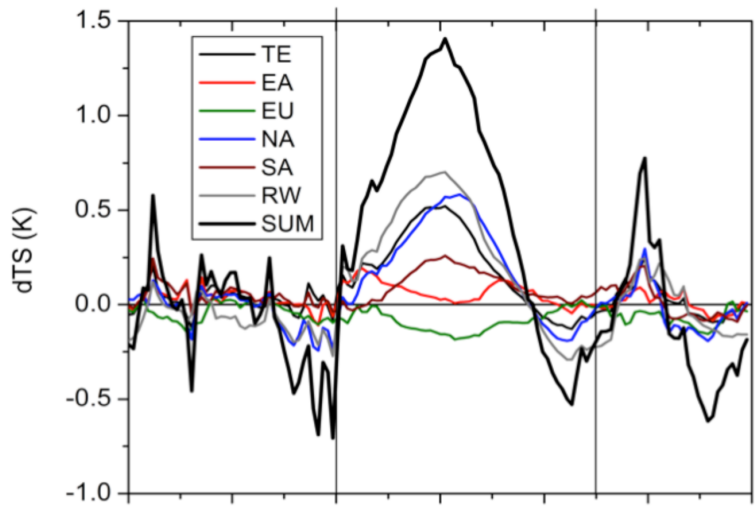

Changes in Lower Tropospheric U (5S-10N Mean)

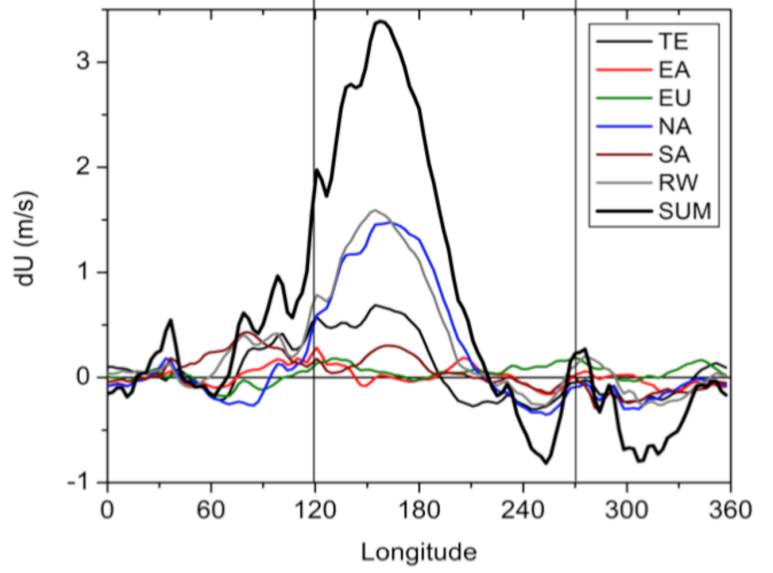

Fig. 6. Meridional mean ( $5 \mathrm{~S}$ to $10 \mathrm{~N}$ ) of $\mathrm{BC}$-caused anomalies of: (the upper panel) surface air temperature (K), and (the lower panel) lower tropospheric zonal component of wind speed $(\mathrm{m} / \mathrm{s})$ derived from various model runs. Results are all year 41-60 means.

hemisphere. However, a substantial difference exists in this effect associated with $\mathrm{BC}$ over different continents, much owing to the short lifetime of $\mathrm{BC}$ and the resultant distribution. The modeled changes in convective precipitation over the Pacific Ocean are found to be most sensitive to the emissions from Central and North America due to a persistent presence of $\mathrm{BC}$ aerosols from these two regions in the lowermost troposphere over the Eastern Pacific. This is consistent with the forcing mechanism suggested by a previous work. The changes in the ITCZ over the Indian and Atlantic Ocean are most sensitive to the emissions from South as well as East Asia and Africa, respectively.

BC aerosols emitted from different continents, when considered alone, often have different effects on atmospheric circulation and precipitation in various locations. The summation of these individual effects mostly exceeds their actual combined effect as shown in the TE run, so that they must offset each other in certain locations. Therefore, although the global mean direct radiative forcing of $\mathrm{BC}$ aerosols is lin- early correlated to the emissions and total atmospheric abundance, the effect of $\mathrm{BC}$ on tropical precipitation (presumably on other climate parameters as well) apparently is not based on this study. However, the fact that despite the differences in pattern and strength, $\mathrm{BC}$ emissions from each of the major source regions all cause an alternation to tropical convective rainfall, implies that cutting emissions from any major region alone can not eliminate this climate effect of BC aerosols. Further work is needed to see whether these conclusions are still valid when the indirect effects of $\mathrm{BC}$ are included.

It is worthy indicating that many aerosol constituents exert a forcing with different sign to that of BC (e.g., scatteringdominant sulfate could have a negative forcing at the top of atmosphere). The response of climate to the total anthropogenic aerosol forcing thus might exhibit different characteristics than those revealed in this study that are caused only by absorbing-dominant BC (actually a strong scattering aerosol as well). Future study will identify the role of BC in affecting the climate responses to the total anthropogenic aerosols.

Acknowledgements. I thank C. Zhang and R. Prinn for useful discussions. I also appreciate M. Mayer, J. Reilly, and M. Babiker for their work that led to the derivation of the $\mathrm{BC}$ emissions data. Two anonymous reviewers along with the guest editor provided many constructive comments. This research was supported by NASA (grant number NNX07AI49G), the NSF (grant number ATM-0329759), and the MIT Global Change Joint Program. I also want to thank the support by the NASA Grant (NNX06AF30G, Global Environmental Change-hazards and regional impacts), and by the technical officers Don Anderson and Lucia Tsaoussi.

Topical Editor F. D'Andrea thanks two anonymous referees for their help in evaluating this paper.

\section{References}

Broccoli, A. J., Dahl, K. A., and Stouffer, R. J.: Response of the ITCZ to Northern Hemisphere cooling, Geophys. Res. Lett., 33, L01702, doi:10.1029/2005GL024546, 2006.

Chung, S. H. and Seinfeld, J. H.: Climate response of direct radiative forcing of anthropogenic black carbon, J. Geophys. Res., 110, D11102, doi:10.1029/2004JD005441, 2005.

Chung, C. E. and Ramanathan, V.: South Asian haze forcing: Remote impacts with implications to ENSO and AO, J. Climate, 16, 1791-1806, 2003.

Emanuel, K. A., Neelin, J. D., and Bretherton, C. S.: On largescale circulations in convecting atmospheres, Q. J. Roy. Meteorol. Soc., 120, 1111-1143, 1994.

Menon, S., Hansen, J., Nazarenko, L., and Luo, Y.: Climate effects of black carbon aerosols in China and India, Science, 297, 22502253, 2002.

Hansen, J., Sato, M., Ruedy, R., Lacis, A., and Oinas, V.: Climate forcings in the Industrial Era, Proc. Natl. Acad. Sci. USA, 97, 9875-9880, 1998.

Haywood, J. M. and Ramaswamy, V.: Global sensitivity studies of the direct radiative forcing due to anthropogenic sulfate and black carbon aerosols, J. Geophys. Res., 103, 6043-6058, 1998. 
Kang, S. M., Held, I. M., Frierson, D. M. W., and Zhao, M.: The response of the ITCZ to extratropical thermal forcing: Idealized slab-ocean experiments with a GCM, J. Climate, 21, 3521-3532, doi:10.1175/2007JCLI2146.1, 2008.

Kiehl, J. T., Hack, J. J., Bonan, G. B., Boville, B. A., Williams, D. L., and Rasch, P. J.: The National Center for Atmospheric Research Community Climate Model: CCM3, J. Climate, 11, 1131-1149, 1998.

Ramanathan, V., Crutzen, P. J., Lelieveld, J., et al.: Indian Ocean Experiment: An integrated analysis of the climate forcing and effects of the great Indo-Asian haze, J. Geophys. Res., 106, 2837128398, 2001.

Randall, D. A., Wood, R. A., Bony, S., Colman, R., Fichefet, T., Fyfe, J., Kattsov, V., Pitman, A., Shukla, J., Srinivasan, J., Stouffer, R. J., Sumi, A., and Taylor, K. E.: Cilmate Models and Their Evaluation, in: Climate Change 2007: The Physical Science Basis. Contribution of Working Group I to the Fourth Assessment Report of the Intergovernmental Panel on Climate Change, edited by: Solomon, S., Qin, D., Manning, M., Chen, Z., Marquis, M., Averyt, K. B., Tignor, M., and Miller, H. L., Cambridge University Press, Cambridge, United Kingdom and New York, NY, USA, 2007.
Roberts, D. L. and Jones, A.: Climate sensitivity to black carbon aerosol from fossil fuel combustion, J. Geophys. Res., 109, D16202, doi:10.1029/2004JD004676, 2004.

Rotstayn, L. D. and Lohmann, U.: Tropical Rainfall Trends and the Indirect Aerosol Effect, J. Climate, 15, 2103-2116, 2002.

Satheesh, S. K. and Ramanathan, V.: Large differences in tropical aerosol forcing at the top of the atmosphere and Earth's surface, Nature, 405, 60-63, 2000.

Wang, C.: A modeling study on the climate impacts of black carbon aerosols, J. Geophys. Res., 109, D03106, doi:10.1029/2003JD004084, 2004.

Wang, C.: Impact of direct radiative forcing of black carbon aerosols on tropical convective precipitation, Geophys. Res. Lett., 34, L05709, doi:10.1029/2006GL028416, 2007. 